\title{
Republicanismo y masonería: la proclividad de los masones andaluces en la Restauración. Los casos de Huelva y de Sevilla
}

\author{
EDUARDO ENRIQUEZ DEL ARBOL
}

\section{PRESENTACION}

El objetivo de esta modesta aportación, que está dentro de la historia de las ideas y de la sociología política, ha sido el conocer cual fuese la adscripción política de los masones de las provincias de Huelva y Sevilla en el período de la Restauración. Es decir, cuales fueron las tendencias que la Institución como tal colectivo y los masones como individuos tuvieron con los distintos partidos políticos, expresadas a través de la documentación de las logias que se conserva en el archivo de Salamanca. Es una primera asomada a unos testimonios más bien escasos, dada la prohibición de hablar de "política" en los templos masónicos y, por lo tanto, las conclusiones son simplemente una aproximación y un punto de partida para ulteriores trabajos.

Se ha confirmado una vez más la dificultad que presenta esa relación de Masonería-Política, si como creemos, no se tienen claros los conceptos de ambos términos.

Las tesis fundamentales serían las siguientes:

I. La Masonería como institución democrática que persigue la emancipación pacífica y progresiva de todos los seres humanos, constituye una escuela de libertades democráticas o foro de encuentro de determinados ideales progresistas y también centro de instrucción socializante con derivaciones políticas. Sus principios trascienden la esfera de lo político para embarcarse en una empresa de ámbito universal. Preconiza la perfección del hombre y de la sociedad a través del lema Libertad, Igualdad, Fraternidad y ello se plasmará de modo individual en adhesiones o simpatías a partidos políticos progresistas y democráticos.

La Masonería sirvió para interiorizar y expandir unos determinados valores ético sociales, y por ende, debió jugar un papel en la formación y preparación política de sus miembros. 
II. En el período del Sexenio, entre los masones sevillanos con actividad politica destacan en número mayoritario los republicanos, seguido de los progresistas y de los monárquicos. Sospechamos que esta combinación puede aplicarse a períodos posteriores relativamente cercanos. Destacamos dos características de acuerdo con la especial idiosincrasia que informa la Masonería a sus miembros: el papel conciliador de los masones de cualquier partido que fuesen y la búsqueda de una República con orden, en 1873.

III. La falta de documentación de contenido "político" en la década de los 80, nos impide saber cual era la posición de los masones de Huelva y Sevilla, aunque podemos suponer que en esa etapa tanto unos como otros se inclinarían mayoritariamente por el republicanismo. Casi el 30\% de los nombres simbólicos escogidos por los masones onubenses del período, en la logia más importante, son republicanos. Detectamos también simpatías por los republicanos militares que se sublevaron, en especial por Villacampa.

IV. Observamos que a los únicos partidos a los que se alude en la correspondencia sostenida entre las logias andaluzas y los Grandes Orientes, son el republicano posibilista, después fusionista, del que era jefe Morayta y el republicano federal.

V. Desde 1891 la posición de las bases es mucho más clara hacia el republicanismo, aunque no en todas las logias. Y serán los talleres bajo los dos Grandes Orientes, el Español y la Gran Logia Simbólica Española, los que nos indiquen de forma más evidente, en la última decada del siglo, una inclinación por la forma republicana. En definitiva, el desplazamiento hacia la izquierda (desde el progresismo al republicanismo) es visible no sólo en las altas instancias de los Grandes Orientes de la última década de la Restauración, sino también en las bases, cuando en algunos momentos éstas, incluso, van más allá de lo sustentado por aquéllas. La declaración de un republicanismo activista consustancial al masón, como expresa una logia de Huelva, es superado por un anarquismo que será posiblemente admitido en Minas de Riotinto mientras había sido execrado en Marchena.

VI. La Masonería estudiada en Sevilla y Huelva para esta etapa de la Restauración, no ofrece en líneas generales, a nuestro entender, una invalidación del principio del "apoliticismo" de la Institución como colectivo, y no hay ningún documento en que se inste a los masones de una logia a declararse o adherirse a algún partido concreto. Sí existen simpatías respecto a movimientos políticos que estuviesen de acuerdo con el espíritu de la Masonería, siendo ello perfectamente admisible. Recordemos el arco político en el que se movían los masones. Dicho esto, debemos añadir que en los últimos años de la Restauración, a fines de siglo, 
encontramos una desviación de la doctrina, cuando hay claros indicios de una "politización" que se da desde la obediencia a algunos talleres hasta la determinación demasiado concreta de los principios de la Orden por parte de algunas logias, derivando en ambos casos hacia el partidismo, lo cual estaba reñido con la "ortodoxia" masónica.

VII. Esta relación de Masonería-Republicanismo debe ser estudiada en los niveles de miembros, logias y Obediencias, en las distintas regiones españolas y en las diferentes etapas históricas a la par que se investigue sobre esa conexión de los masones con la vida política del XIX. Sólo así podremos completar y elevar a definitivas estas conclusiones.

\section{INTRODUCCION}

Los estudios que han podido realizarse sobre la Masonería para colmar esta laguna de la historia de España, como lo expresara el profesor Artola hace tiempo, gracias a la apertura del rico Archivo de Salamanca, han permitido el que hoy sepamos mucho más de esta Asociación, que provocó los más variados juicios y concitó al mismo tiempo las pasiones más desatadas. Ya pasó aquella época en que una pseudohistoria vigente, más o menos "oficial", servía de recurso fácil a una toma de posición ideológica, basada en apriorismos gratuitos y que se justificaba al no existir ninguna base documental.

Después de los cinco symposiums sobre la Masonería que hemos celebrado en los últimos años y de una veintena de tesis doctorales leídas o en elaboración, se ha cubierto la h istoria interna de la Institución para el siglo XIX y en gran parte del XX, lo cual nos ha permitido reconstruir una Masonería que ni tuvo la importancia que sus enemigos le achacaron, ni tampoco fue una mera sociedad desvinculada o ajena a los asuntos sociales, políticos o religiosos. Al mismo tiempo que se elaboraba esta historia interna se ha pasado a la investigación de la relación de la Masonería (y de sus miembros) con el mundo "profano" que la circundaba, donde el posible maridaje entre Masonería y Republicanismo ya ha tenido sus investigadores (1).

(1) Véase a título de ejemplo, los temas dedicados a ello en el IV Symposium celebrado en Alicante en 1989, y que se englobaban bajo el epigrafe de "Masonería y Republicanismo" sobre distintos aspectos de esa posible relación: MARTIN, L.P.: "La Logia y la Tribuna: Los políticos masones de Castilla y León (1868-1900)"; VALIN FERNANDEZ, A.: "La Masonería como vehículo propagador del liberalismo político: El caso gallego"; ALVAREZ REY, L.: "La Masonería en Sevilla entre el compromiso y la militancia política"; CLARA, J.: "Masones en los Gobiernos de la Generalitat de Cataluña (1931-1933); REQUENA GALLEGO, M.: "Masonería y política, Albacete (1928-1933)", RODRIGUEZ DE CORO F.; "El masón Francisco Jiménez, diputado por Guipúzcoa en las Constituyentes de 1931", etc., etc. (Masonería, Revolución y Reacción, Alicante, Diputación Provincial, 1990, vol. I, pp. 127-336). 
Es evidente que una mayor profundización sobre la Institución masónica desde distintos sectores ha originado el planteamiento de problemas metodológicos, históricos e incluso semánticos sobre términos ambiguos o poco desarrollados conceptualmente, que deberán resolverse en el futuro, dejando siempre abierto el tema a la expectativa de nuevos descubrimientos que confirmen, corrijan o maticen las líneas ya elaboradas de la investigación (2).

Completando la historia interna de la Institución, nos interesaba saber si a través de la documentación de las logias podíamos extraer sus inclinaciones políticas. Este es el tema del presente trabajo, en donde tras abundar en el concepto de Masonería y en sus objetivos no políticos, nos proponemos mostrar unas pautas de referencia en la relación entre Republicanismo y Masonería en la Andalucía de la Restauración (Huelva y Sevilla), basadas, como hemos dicho, en las fuentes conservadas en el archivo salmantino, teniendo en cuenta que ello es sólo un punto de partida para ulteriores estudios.

\section{EL CONCEPTO DE MASONERIA Y SUS OBJETIVOS NO POIITICOS}

Antes de pasar adelante, y para evitar equívocos, debemos hacer referencia a lo que se entiende por Masonería. Podemos invocar la definición que se daba en la época en que se ubica nuestra investigación. Así en el Cuerpo de Derecho Masónico español, publicado en 1880, se dice: "La Francmasonería es un sistema de filosofía que promueve la civilización, ejerce la beneficencia y tiende a purificar el corazón, a mejorar las costumbres, a mantener el honor en los sentimientos y la cultura en los modales" (3).

Ragón un historiador francés, muy citado en la prensa masónica española en tiempos de la Restauración, pocos años antes, en su Manual de Aprendiz Masón, nos dice: "La Francmasonería es una

(2) Uno de los problemas básicos ha sido la relación entre la Masonería y la política, desde los puntos de vista teórico y práctico, que intentamos esclarecer en un estudio que vio la luz en 1989 (ENRIQUEZ DEL ARBOL, E.: "La Masonería española y la política iobjetivos comunes?", en Masoneria, Politica y Sociedad, Zaragoza, Centro de Estudios Históricos de la Masonería Española, 1989, vol. I, pp. 3-23). Otro de los problemas que nos planteábamos al estudiar las actividades de los miembros de la Masonería sevillana durante la época del Sexenio, fue la distinción entre "adscripción política" y "actividades política", en relación con la "adscripción masónica" en el tiempo (ARIAS CASTAÑON, E. y ENRIQUEZ DEL ARBOL, E.: "Masonería y política en la Sevilla del Sexenio Democrático (1868-1874)". Ibidem., vol. I, p. 35 y ss.).

(3) Cuerpo de Derecho Masónico Español, Freemason's Hall Office, 1889, p. 11. 
sociedad íntima de hombres escogidos, cuya doctrina tiene por base el amor a Dios, bajo el nombre de Gran Arquitecto del Universo, y el amor a los hombres; por regla, la religión natural y la moral universal. Reconoce por causa, la verdad, la luz, la libertad; por principios, la igualdad, la fraternidad, la caridad; por armas, la virtud, la sociabilidad, el progreso y por objeto, el perfeccionamiento y la felicidad de la humanidad a la que trata de reunir bajo una sola bandera" (4).

Por las mismas fechas, en la base 1 de las Constituciones del Gran Oriente de España, publicadas en 1871, se resaltan las tres ideas fundamentales: a) Ser la Masonería una sociedad filantrópica moral y fraternal; b) Acatamiento de la autoridad legítima; c) Prohibición de conspiración, precisamente para dejar bien sentada la falsedad de tal conducta que le era atribuida.

$\mathrm{Y}$ ateniéndonos a la respuesta que algunos compañeros gaditanos dieron al Venerable de la logia Tolerancia y Fraternidad, de Cádiz, bajo los auspicios del Gran Oriente Lusitano, en fecha tan temprana como 1867, tendríamos esta definición:

"La Masonería era una institución filosófica, filantrópica y progresiva, que tenía por base la existencia de Dios y la inmortalidad del alma, por objeto la práctica de la beneficencia, el estudio de la moral universal, de la ciencia, de las artes, y la práctica de todas las virtudes, y por divisa, "Libertad, Igualdad, Fraternidad" (5).

Tras estas definiciones, repetitivas en lo fundamental pero que pueden dar lugar a pensar en una sociedad dirigida también a la política, debemos subrayar una prohibición que la Masonería intentará cumplir en todas las épocas, cual es la de tratar de asuntos religiosos o políticos en la logia, lo que equivalía a la superación de partidismos de esta índole, que pudiesen conducir al enfrentamiento entre los masones. De ello bien cuidaban algunos altos organismos de la Institución. Así hemos encontrado en la investigación que realizamos sobre el Boletin del Gran Oriente de España, durante el Sexenio Democrático, que éste tuvo que llamar la atención a las logias para impedir que en ellas se hablara de cuestiones políticas, lo que demuestra que era difícil sustraerse a éstó (6). Fueron, en verdad,

(4) RAGON, J.M.: Francmasoneria. Ritual del grado de Aprendiz masón. Barcelona, Ed. Salvador Manero, 1870, pp. 21-22.

(5) Colección documental de la logia "Tolerancia y Fraternidad n. 11" de Cádiz, acta de la sesión celebrada el 16 de febrero de 1867 (A.H.N.-S.G.C. (Masonería), Legajo 479-A-1, Mss.).

(6) Así lo advierte en las dos Circulares de 15 de mayo y 1 de julio de 1871 el Boletin (Cfr. ENRIQUEZ DEL ARBOL, E.: Art. cit: p. 22). 
casos raros en los que se tocaran temas políticos a favor de cualquier partidismo. Y sólo se daba entrada a ideas generales que no llevasen nunca la adscripción a una determinada forma de gobierno o partido político que pudiese provocar rencillas o la separación entre hermanos.

Sin embargo, sí hubo una determinada "política" que los masones defendían, distinta de lo que se llamaba la "política" en sentido peyorativo (7). La Masonería, por sus principios ideológicos de la Ilustración, de por sí revolucionarios, por los cuales persigue la emancipación pacífica y progresiva de todos los seres humanos, trasciende la esfera de lo político para embarcarse en una empresa de ámbito universal. Este fundamento en la moral y en la ciencia, en definitiva en el progreso, hace que tome partido por una serie de valores liberales o demócratas, destacando la trilogía: Libertad, igualdad y fraternidad. El principio de libertad en todas sus manifestaciones, constituye los derechos del hombre, válidos para todos los ciudadanos de una sociedad democrática. Se reconoce a todos los hombres iguales derechos ante Dios, la Naturaleza y la Sociedad. De ello derivaba una posición, que podríamos llamar "política", tomando el término en sentido amplio, frente a la discriminación racial, jurídica, económica, religiosa o de cualquier otro tipo (8). Así no es extraño que en el cambio de la Monarquía amadeísta a la República, el Boletin acogiese en sus páginas el encomio de una logia de Uruguay por el nuevo Régimen, ya que prometía implantar en España una nueva era de libertad y de justicia (9).

Hay pues, desde sus inicios, por su misma formación, una proclividad de la Masonería, sea entendida en sus más altos representantes orgánicos (Grandes Maestres, Comendadores, etc.), como en los masones de a pie, hacia la vertientes más progresistas de la política española descartadas la intransigencia y la intolerancia, y por el momento, la revolución. No es extraño que sus figuras se afiliaran a esas corrientes, ya que existía la afinidad de sus ideales éticos con los objetivos que encarnaban los partidos más avanzados: el liberal progresista, el democrático (10) y el republicano con todos sus matices y divisiones

(7) Cfr. nota 1 (Ibidem., pp. 3-23).

(8) Ibidem., p. 17.

(9) Ibidem., p. 20.

(10) La dicotomía monárquico-democrática y republicano-democrática se esboza en el Bienio Progresista, al contrario de los que apuntaba Carro sobre la escisión democrática de 1869 en monárquicos y republicanos. Sería esta agrupación, en los primeros años del Sexenio, la más poderosa (progresistas, unionistas y demócratas). Lo que separaba a los progresistas de los demócratas era la cuestión del sufragio universal, no aceptado por el grupo progresista, y es curioso observar como el mismo Sagasta tan reacio a ello, lo propusiera en 1885 y lo llevara a cabo en 1890 con el impulso de Castelar. 
(11), pero sin quedar reducido a éstos el espacio político de los masones. Ideales éticos por lo tanto, que tenían su transferencia o plasmación política.

No olvidemos que el motor de la Revolución de 1868, el general Prim perteneció a la Institución (12). Y uno de los artífices de la Restauración, complemento necesario al sistema canovista y jefe del partido liberal es Práxedes Mateo Sagasta, que fue proclamado Gran Maestre del Oriente de España, el 7 de abril de 1876 (13).

Obviamente con ello no quedan resueltas todas las interrogantes, que se plantean en torno a la doble ruptura: de un lado, la de la unidad masónica, es decir, el surgimiento de diversas Obediencias o altos organismos con diversidad de orientaciones (14), y del otro, la separación de las bases (los masones de las logias) con respecto a la cúspide. Repetimos, todo ello sin que se llegara a quebrantar el principio del "apoliticismo" (15).

En cuanto al primer problema, el fenómeno se produce ya desde los primeros momentos de la Revolución septembrina y en líneas generales podemos admitir orientaciones más o menos "politizadas", usando este vocablo de modo muy genérico, teniendo en cuenta la adscripción de sus miembros a determinados partidos políticos. En el Sexenio, hay una pluralidad ideológica aunque el estudio de Sevilla,

(11) Unitarios o federales que ya aparece en los primros momentos revolucionarios. Estos últimos en "benévolos" e "intransigentes"; aquéllos en posibilistas y no castelarinos, etc.

(12) Como afirma el profesor Ferrer Benimeli las figuras de Juan Prim y de Amadeo de Saboya como masones están todavía esperando sus correspondientes estudios (FERRER BENIMELI, J.A.: Masoneria española contemporánea. Madrid, Siglo XXI, 1980 , vol. II, pp. 6 y 7 ).

(13) La lista de masones ocupando cargos políticos sería interminable: Manuel Ruiz Zorrilla que fue Gran Comendador y Gran Maestre de 1870 a 1874; Juan de la Somera que sustituyó a Zorrilla; José Muro Salgado; Antonio Romero Ortiz, ministro de Gracia y Justicia, que sustituyó a Sagasta en la suprema jefatura del Oriente masónico el 10 de mayo dé 1881; Manuel Becerra reemplaza al anterior en 21 de julio de 1884, etc. De otras "Obediencias", Ramón María Calatrava, el marqués de Seoane, Miguel Morayta, Eleuterio Maisonnave, Francisco Rispa y Perpiñá, Enrique Pérez de Guzmán, Anselmo Lorenzo, Segismundo Moret, etc. etc.

(14) Es de resaltar la búsqueda de auspicios de muchas logias andaluzas y canarias en el Gran Oriente Lusitano de Lisboa desde 1867, desechando a los Orientes españoles. Cuando se produzca la ruptura con el Oriente portugués, en 1878, se unirán para formar otra potencia independiente: la Gran Logia Simbólica Independiente Española con sede en Sevilla.

(15) Continuamos sustentando la tesis de los valores ético-políticos de la Masonería que podían dar lugar a actitudes políticas, pero sin que se pudiese tachar a la Institución como una sociedad "política" y, al mismo tiempo, de la doble dialéctica a la que se enfrentará la Masonería. Véasé nota 2. 
como veremos más adelante, nos muestre un predominio republicano en las logias del Gran Oriente Lusitano. Ello no invalida la tolerancia de la que la Masonería hacía gala hacia las distintas doctrinas políticas que podían hallarse comprendidas en el campo de sus valores éticos.

Respecto a la segunda cuestión, esa disparidad y a la postre, distanciamiento de las bases con respecto a la jerarquía ocurre en el Gran Oriente de España, el más importante en la primera etapa de la Restauración, ya que sus jefes, Sagasta o Becerra, están por la labor en pro de la dinastía borbónica, siendo el primero pieza fundamental en el plan canovista del bipartidismo. Muchos si no militan en las filas del progresismo radical, transformado en republicano, de Ruiz Zorrilla, el desterrado en París, al menos simpatizarán con sus ideas, demostrándolo en actos de solidaridad tras las fallidas sublevaciones de 1883 y 1884. ¿Influyó ese idstanciamiento en la descomposición del Gran Oriente de España? Es significativo que Miguel Morayta, todavía republicano posibilista, que había sido alto cargo en aquel organismo, funde el Gran Oriente Español y lo convierta en el grupo masónico más importante y mejor organizado a partir de 1889 (16). Desde 1891 Morayta será el jefe de una de las ramas en que se dividió el partido posibilista (17).

Otro Gran Oriente que nace en el año crítico de 1887, esta vez de la fragmentación del Gran Oriente Nacional, es el que dirige Alfredo Vega, que sería sustituido en 1893 por Rispa y Perpiña, que había sido un destacado federal "intransigente" y más tarde unos de los componentes de la Junta del Partido Federal Orgánico en 1883.

Lo que sí es indudable, a nuestro parecer, y' lo hemos reseñado, es que podría considerarse a la Masonería como una institución instructiva, una escuela de libertades democráticas o foro de encuentro de determinados ideales, en resumen, una escuela de socialización "política" del español de su tiempo (18). De todos modos si con ello la Masonería sirvió de centro de reunión para interiorizar y expandir unos determinados valores ético sociales, y por ende, al mismo tiempo, políticos, tiene un interés histórico indudable.

(16) No obstante, la afirmación de Sánchez Ferré que ello "representa el triunfo del republicanismo en las filas masónicas", había que matizarla (SANCHEZ FERRE, P.: "La Masonería en Cataluña (1869-1936)" en Aportes. Revista de Historia Contemporânea, Año IV, n. 10, (Madrid), mayo 1989, p. 47). A partir de 1898, algunas logias catalanas serán proclives al lerrouxismo (Ibidem., p. 48).

(17) La otra será la Constitucional Republicana de Carvajal y un tercer grupo que engrosaría las filas del partido liberal monárquico.

(18) ENRIQUEZ DEL ARBOL, E.: Art. cit., p. 18. Todavía está por aclarar el papel que jugó la logia en la formación política de los masones. 
¿Fue la logia masónica un centro de captación de proselitismo "político"? Podemos pensarlo si damos a este término un significado amplio, en cuanto que las ideas de los principios masónicos se dirigían a la defensa de los derechos humanos y hacia una sociedad democrática, lo que llevaba como consecuencia, por una parte, la admisión de personas acordes con tales ideales y por otra, un comportamiento político determinado.

Todo ello provocaba la doble marginación de la Masonería: ser una sociedad "secreta" amén de hallarse en unas coordenadas que podían considerarse peligrosas políticamente al estar fuera del régimen.

Pero si bien la Masonería como organización no estuvo adherida a ningún bando político, aunque se ponga a veces en tela de juicio su apoliticismo, es interesante para la historia de las ideas y para la historia socio-política, el conocer cuáles fueron las tendencias que la Institución como tal colectivo y los masones como individuos tuvieron con los distintos partidos políticos. Ello a pesar de la distinción que debemos hacer entre la "Obediencia" como potencia suprema y la logia como célula básica en las que estaba prohibido, al menos formalmente, hablar de cuestiones políticas o religiosas concretas (o partidistas) y el comportamiento de los masones como ciudadanos. Vinculaciones de éstos con el republicanismo, como hemos apuntado líneas arriba, que se harán más evidentes a medida que transcurran los años en el período de la Restauración.

\section{EL ANTECEDENTE ANDALUZ: REPUBLICANOS Y MASONERIA SEVILLANA EN EL SEXENIO}

Si la revolución de 1868 dio paso a una transformación fundamental del panorama político español tras la época isabelina, con el surgir, entre otros fenómenos, del liberalismo radical, supuso también el momento de aparición de una Masonería organizada, de la que tenemos constancia histórica gracias a las fuentes documentales conservadas en el Archivo salmantino.

En el estudio que realizamos sobre la Masonería sevillana aparecía ésta ligada estrechamente a la Revolución septembrina, y el periódico El Clarín, revolucionario y masónico a decir de Vicente Lafuente, afirmaría que "la sedición militar del 18 de septiembre de 1868 había sido promovida en Cádiz y en Sevilla, por la logia masónica La Fraternidad Ibérica, a la cual pertenecían casi todos los exnobles marinos". La logia, calificada como "cimbria" o republicana, había sido fundada el 15 de octubre de 1867, es decir, un año antes de la Septembrina. 
Una vez completada la historia interna de la asociación sevillana, se elaboró un trabajo conjunto para desentrañar las relaciones entre Masonería y partidos políticos en el Sexenio Democrático. Arias Castañón puso en evidencia la intervención demócrata y los republicanos que fueron masones (19), a pesar de que la mayoría de los miembros sevillanos de la Institución, de los que tenemos constancia en este periodo, no tuvieran una práctica política conocida. Se pudieron clasificar los masones con actividad política, en tres grandes grupos y unauq en las logias sevillanas del Sexenio encontramos representantes de las más importantes tendencias, hay un predominio de los republicanos federales sobre el resto, en número de 25 (20), mientras que los progresistas democráticos fueron 9 (21), y los monárquicos de tono conservador, 6 .

Los masones se distinguieron por buscar un enetendimiento de progresistas demócratas y republicanos, primero, en torno a la candidatura portuguesa del príncipe Fernando de Coburgo, proyecto lanzado en 1868, por el director y el redactor del diario La Andalucía, Francisco María Tobino y Manuel Gómez Zarzuela, que ingresarían en la Institución meses más tarde, y segundo, por la defensa de un republicanismo federal conciliador que realizan los hermanos Rubio Gali. Después tanto los progresistas democráticos y los monárquicos lanzaron una línea monárquica democrática, propuesta progresista democrática primero (1868-1870) y democrática radical, más tarde (1871-1872).

Fue destacada la intervención en todos los acontecimientos, incluso en el momento de la Revolución, de Antonio Machado Núñez, abuelo de los Machado y masón a partir de 1869, perteneciente a la logia Fraternidad Ibérica, uno de los representantes progresistas de la Primera Junta revolucionaria de Sevilla y después gobernador civil de la provincia aupado tras la subida de otro sevillano al Ministerio de la Gobernación, Nicolás María Rivero. Machado fue un defensor incansable de la vertiente democrática de la Revolución.

En 1871 el progresismo democrático sevillano se hace radical de Ruiz Zorrilla. La presidencia del Comité Progresista democrático radical está en manos de un masón también, Joaquín Casanovas Ferrán.

(19) ARIAS CASTAÑON, E. y ENRIQUEZ DEL ARBOL, E.: Art. cit., p. 51.

(20) Destacaron, José Rubio Gali, Miguel Alsina, Francisco María Tobino, Manuel Gómez Zarzuela, Antonio Alvarez de los Corrales, Luis Escudero Peroso, José Alvarez Astolfi, Luis de Góngora Joanico, etc.

(21) Entre ellos el catedrático Antonio Machado Núñez, Francisco Bernáldez, Joaquín Casanovas Ferrán, Laureano Rodríguez de los Conchas, etc. 
Durante la I República, la conexión entre Masonería y Republicanismo federal, se hizo más evidente en 1873. Desempeñaron los masones importantes actividades políticas defendiendo una república de orden (22). Intentaron tres masones que ocupaban los cargos de presidente vicepresidente, secretario y vocal del Comité Repúblicano Federal, organizar el republicanismo federal sevillano en torno a la opción Castelar (23).

Lo que todo ello nos demuestra es que la selección del personal de la Masonería no dejaba lugar a dudas sobre una determinada mentalidad, exigida de acuerdo con los fundamentos de la Institución, que desde luego podía ser reformista, a lo más de tinte pequeño burgués, incluso llevada al extremo, pero difícilmente "revolucionaria". Por ello, la Masonería en su defensa de la democracia debía estar más cerca del movimiento progresista-democrático y republicano que de la Monarquía, sostenida por las fuerzas conservadoras y un liberalismo más moderado, y por lo tanto más reacio a aplicar las consignas revolucionarias de la libertad y de los derechos del hombre.

\section{LA PROCLIVIDAD DE LOS MASONES HACIA EL REPUBLICANISMO EN LA RESTAURACION: LOS CASOS DE HUELVA Y SEVILLA}

Abundando en lo expuesto anteriormente, en investigaciones realizadas hasta ahora en cuanto a la ideología a través de los órganos oficiales Boletines y Gacetas, de las respectivas Obediciencias, hemos notado una mayor "politización" en los Orientes que subsisten en la década de los 90, en el sentido que desde las páginas de sus órganos oficiales se decantan por un determinado sistema político: la República. Recordemós el Gran Oriente Español, que dirige Miguel Morayta; el Gran Consejo General Ibérico (vinculado a la Gran Logia Simbólica Española del Rito del Memphis y Mizraim) y el Gran Oriente Ibérico, aunque éste en menor grado.

En el trabajo que realizamos sobre la Masonería en las provincias de Huelva y Sevilla, constatamos que si bien en el interior de las logia convivian tendencias políticas de cualquier signo, éstas siempre se movían dentro de corrientes liberales progresistas.

Existen determinaciones en el momento de la fundación de los talleres sobre metas a conseguir como son la ilustración, la lucha contra el oscurantismo y la ignorancia, la defensa de los derechos huma-

(22) Seis fueron diputados provinciales, siete concejales y cuatro directivos del Casino.

(23) Ibidem., p. 51. 
nos y por ende, la regeneración del individuo y de la sociedad, o el deseo de prosperidad para la querida Patria (24), pero todo ello sin concretarse en partidismos políticos.

Es evidente que la composición social de las logias es un factor a tener en cuenta en las manifestaciones de tipo "político" que realizan y que conocemos dirigidas a sus respectivos poderes. Serán precisamente las logias donde acuciaban más los problemas sociales aquellas que expresen una mayor preocupación por cuestiones políticas.

En la investigación realizada hemos extraido de las fuentes documentales algunos ejemplos, los más significativos, en donde aparecen las preocupaciones políticas. Ya sabemos que en la logia no se podía hablar de cuestiones partidistas, de ahí que los ejemplos encontrados sean mínimos. Con ellos y con las manifestaciones que aparecen a través de la correspondencia mantenida entre los miembros de la logia y sus superiores, hemos podido deducir el pensamiento y la actividad de los masones.

\subsection{El caso de Huelva}

Aunque la Masonería en Huelva aparece en 1870 su existencia es casi desconocida por no estar documentada. Su auge tiene lugar a partir de 1881, coincidiendo con la subida de Sagasta al poder, (hasta 1885), fundándose entonces los centros más importantes. No obstante, la erección de logias continuaría en los años finales de los 80 y durante la siguiente década, aunque con menos empuje. La Obediencia más importante fue la del Gran Oriente Nacional de España en la década de los 80, seguida por el Gran Oriente Español en la década siguiente.

Para nuestro propósito son los talleres pertenecientes a esta última Obediencia, la que lidera Morayta, los que tienen mayor interés. La relación con la política de modo más explícito, aparece en logias cercanas ya al desastre de 1898.

Dado que en los primeros años de la Restauración hay escasez de documentación de los centros masónicos y cuando existe trata sólo de trámites burocráticos, nos interesaba estudiar unas posibles referencias socio-culturales de la Institución y en especial una ideología encaminada hacia la esfera de lo político. Sobre una logia, la Moralidad $n$. 160 , la más importante de Huelva, elaboramos- un trabajo acerca de los nombres simbólicos y su significado socio-político. En él analizábamos dichos nombres agrupándolos en seis categorías (Espiritual-religiosa; Intelectual filosófica; Poder-Gobernante; Republicanismo; e Inventor artista). A su vez esas categorías las encuadrábamos en el

(24) Tal como aparece en la logia Virtud y Progreso, de Zalamea la Real (Huelva). 
tiempo y, par ala Edad Contemporánea que presentaba una cifra más numerosa de nombres simbólicos, advertíamos que la mayor parte de los personajes escogidos lo eran del republicanismo (25).

Sobre la selección del personal que entraba en la Masonería, poseemos dos ejemplos. El primero es bastante indicativo, aunque no nos sirva de modelo único porque ignoramos como era el de los restantes talleres onubenses. Se trata del formulario de petición de ingreso perteneciente a la logia Luz y Trabajo n. 32 de Huelva, y encontrado en la documentación de la de Aroche, que nos habla de una discriminación con respecto al "jesuitismo" en el momento de la admisión de los masones en las células auspiciadas por la Gran Logia Simbólica Independiente, el alto organismo masónico sevillano:

"Los buenos antecedentes que tengo de la sublime Institución masónica me hacen desear pertenecer a ella sin miras de lucro personal ni impulsado por pasiones bastardas.

Amo la perfección del hombre y siento entusiasmo por el progreso de la humanidad. Como obrero de la regeneración. social, pido un lugar en vuestros trabajos, declarando bajo mi palabra de honor no haber hecho igual solicitud en otra corporación masónica, ni pertenecer a sociedad alguna que tenga conexión con el jesuitismo y prometiendo someterme gustoso a vuestras Leyes y Reglamentos" (26).

En el otro ejemplo se plantearon dudas sobre si una determinada tendencia política, la que conocemos se refiere al anarquismo o acracia, podía conciliarse con la actividad masónica (27). La respuesta no la sabemos. Si en este Gran Oriente ello podía ofrecer dificultades, no así en la Gran Logia Simbólica Española del Rito de Memphis y Mizraim (28).

(25) "Todo ello nos indica que la connotación de republicanos era quizá la más importante a la hora de elegir un gobernante o un intelectual". De los 108 miembros de la logia los nombres republicanos fueron 29 (ENRIQUEZ DEL ARBOL, E.: "Aproximación metodológica a los nombres simbólicos masónicos en un caso particular: la logia Moralidad n. 160 de Huelva", en Del Antiguo al Nuevo Régimen. Estudios en Homenaje al Profesor Cepeda Adán, Granada, Universidad, 1986, pp. 213-243).

(26) "Me llamo... Nací... Provincia... el día... de estado... de religión... de profesión... y domiciliado... calle del... núm... Huelva... de... de 188...". (Colección documental de la logia Hijos de la Luz de Aroche, A.H.N. - S.G.C. (Masonería), Legajo 757-A-10).

(27) Así lo propuso la Fraternidad de Minas de Riotinto al Gran Consejo del Gran Oriente Español, en 1899.

(28) Donde una de las logias catalanas, la obrera Emancipación de Sallent asume el ideal ácrata como ideal masónico, a la altura de 1896 (Cfr. ENRIQUEZ DEL ARBOL, E.; "Al filo de un centenario: El último Gran Oriente hispano del siglo XIX: La fundación de la Gran Logia Simbólica del Rito Primitivo y Oriental de Memphis y Mizraim (1889-1989)", en Masoneria, Revolyción y Reacción, Alicante, Diputación Provincial, 1990, pp. 1016-1017. 
Respecto a la conexión Masonería-republicanismo, encontramos una defensa del republicanismo en los escasos documentos onubenses que a ello hacen referencia y que aquí nos interesa destacar: se llegará en la logia Hijos de la Luz de Aroche, al extremo de considerar que para ser buen masón habia de ser ferviente republicano y librepensador. Es uno de los talleres más interesantes de Huelva (29). Debemos añadir que si esto no es una expresión general de las logias, que no aluden para nada a esta problemática política, si lo encontramos en los Boletines de los Grandes Orientes, como el Español de Morayta o el de la Gran Logia Simbólica Española del marqués de Santa Marta. No es extraño que surgiera el rechazo a la doctrinas monárquicas por ser las que mantienen esa situación que se considera injusta, contraria al progreso de la Humanidad, inconciliable con la defensa de los derechos del hombre, actitud que se compartía con el republicanismo, que creía que los términos Democracia y Monarquía no sólo eran antagonistas sino excluyentes (30).

En consonancia con lo expuesto, especial consideración ofrece una de las "planchas" de la logia precitada, cuyos miembros se declaran pertenecientes al Directorio de Fusión Republicana (recordemos que estamos en 1897, donde al parecer las ideas básicas que sustentan se encaminaban a una revolución que vendría marcada con el signo del republicanismo (31). En la logia todos convenían, al parecer, en que el remedio para los males del país estaba en esa revolución bajo el marchamo de republicanismo. Ahora bien al decir que en el taller había de los dos partidos turnantes en el poder y con grandes influencias, pensamos que los

(29) Robustiano Román, platero y natural de Gaucín (Málaga), va a ser el alma del taller. Curiosa su composición en una de las coyunturas más difíciles de la Masonería española: un platero, dos propietarios, un secretario de Ayuntamiento, un farmacéutico, un perfumista, dos militares, tres zapateros, dos comerciantes, un albañil y un carpintero.

(30) Sobre todo leyendo determinados editoriales de los Boletines aludidos (el Boletín del Grande Oriente Española y el Boletin de Procedimientos de la Gran Logia Simbólica Española)

(31) "Los grandes acontecimientos que es de esperar se desarrollen en España con motivo de los fracasos, crisis y vejámenes que estamos sufriendo, obliga a que la imaginación de los buenos patriotas concivan (sic) ideas regeneradoras que nos priven de todos estos males y como ninguna más que la revolución puede llevarnos a el apropio (sic) y la gloria; los obr. de esta Respetable logia, por conducto de su Gr. Or. Español y a la vez miembros del Directorio de Fusión Republicana se comprometen no sólo a secundar todas las órdenes que de ese centro se recivan (sic), sino también a obrar con los medios que nos presten parar ello nuestra vida, nuestra fortuna, y lo más sagrado de todo, nuestra Fe que es el emplema más hermoso de todo ideal (...)" (Plancha sin fecha, aunque colegimos que debió ser en 1897, colección documental de la logia Hijos de la Luz, de Aroche, en A.H.N.-S.G.C. (Masonería), Legajo 757-A-10). 
mismos que hacían esta declaración eran los únicos que podían tener tales influencias: el Secretario de Ayuntamiento, el farmacéutico, el propietario, el negociante y no los que faltaban en el escrito, ni por su profesión ni por su edad: el albañil, el carpintero y el zapatero. De ahí la frase que aparece y que es explícita: "Pero esto nos sirve sólo para tener afianzada la palanca y obrar con gran conocimiento de causa en nuestros trabajos internos". ¿Era un doble comportamiento político?

Esto debió alarmar al Gran Oriente Español que no contestó a las diferentes misivas que los onubenses le enviaron. Por ello, ante este silencio, la logia estuvo a punto de romper sus relaciones con el alto organismo madrileño que la auspiciaba.

En un momento, la misma logia teme una persecución por parte de la autoridad, en agosto de 1897. Era fácil para el poder establecer la conexión entre Masonería-Republicanismo, republicanismo-asalto del poder, aunque para estas fechas de fines de siglo las preocupaciones esenciales del Gobierno estuviesen puestas en la revolución social. No hay que olvidar que Miguel Morayta, Gran Maestre desde 1887 del Gran Oriente, después denominado Español, Obediencia a la que pertenecía la logia citada, es a partir de 1891, el jefe de una de las ramas del partido posibilista.

\subsection{El caso de Sevilla}

Si en Huelva son' escasos los indicios de inclinaciones hacia regímenes concretos o actitudes políticas definidas, en Sevilla, como veremos más adelante, esta Masonería andaluza bien como tal Masonería o bien a través de sus miembros, toma una actitud más crítica ante las cuestiones que el país tenía planteadas y abre caminos para la solución de esos problemas, aunque guardándose mucho de tomar partido por una solución política concreta, si bien coincidiendo o simpatizando con las tesis del republicanismo.

Así veamos qué pensaban los masones sevillanos de su ciudad y del papel que desempeñaba la Institución. De un modo bastante simplista se hablaria de ello en la logia Verdad n. 115:

"En Sevilla que por condiciones especiales se dividen sus moradores en dos corrientes: la una lleva a las clases más opulehtas a los jubileos, novenas y procesiones, la otra a los espectáculos de la Tauromaquia, a las bacanales y al desorden moral, con detrimento del buen sentido, en Sevilla es necesaria la Mas. para que sea el baluarte, el núcleo donde se agrupen los que nos piensan de aquellos modos (...)" (32).

(32) Plancha de la logia al Gran Consejo de la Orden, 13-I-1895 (Ibidem.). 
Los masones sevillanos, como veíamos páginas arriba, están presentes en los primeros momentos de la Revolución de 1868. Su influjo fue estudiado en el apartado correspondiente al Sexenio.

A pesar de los nuevos aires de la Restauración, la Institución en Sevilla no decae (33). Sin embargo, hay una inflexión que coincide con el inicio de la regencia de María Cristina. Aí se produce un cierto auge con motivo de la Ley de Asociaciones de 1887, debida al Gobierno sagastino y que van a crear expectativas de unión de los distintos grupos masónicos a partir de este momento (34).

En definitiva, el crecimiento mayor se producirá en los bienios 1872-1874, 1882-1884 y $1890-1892$.

En cuanto a las Obediencias, se destaca hasta 1878 el Gran Oriente Lusitano, que será sustituido por la Confederación Masónica con sede en Sevilla que dará lugar al Gran Logia Simbólica Independiente Española. Poca importancia tendrán el Gran Oriente de España y el Gran Oriente Nacional. A partir de 1888 el Gran Oriente Nacional de Vega (después Gran Oriente Ibérico) y el Gran Oriente Español de Morayta, intentarán poner pie en la capital pero no con mucho éxito (35).

Las fundaciones desde esa fecha serán principalmente debidas al Soberano Gran Consejo General Ibérico y Gran Logia Simbólica del Rito de Memphis y Mizraim (36), el gran protagonista de la Masonería sevillana en la década de 1890-1900, que llegará a auspiciar 22 centros en Sevilla, diseminados en toda la provincia y sobre la cual avanzamos un estudio recientemente (37).

$\mathrm{Y}$ debemos añadir lo que ya dijimos sobre Huelva, que son los talleres masónicos, pertenecientes a estos últimos Grandes Orientes, los que dejan entrever un decantamiento político.

(33) Continúan las logias del Sexenio. El ejemplo de la Numantina, cuyos miembros ascienden a 136, de los que son nuevos 84 en el periodo de 1873-1877, es significativo al igual que sucede con la Razón n. 47 y la Graco n. 18, que de los 18 miembros fundadores en 1873, se pasan a 101 en 1881.

(34) Una de las logias de las que poseemos mayor información, sorprendentemente, es de la Martía n. 385, de Marchena, que nace en 1888.

(35) La primera con dos centros (Caridad $n$. 75 y Fe $n$. 121) y la segunda con tres (Martía n. 385 de Marchena, la Razón n. 98 y la Verdad n. 115 de Sevilla).

(36) Eran células, que por la única fuente del Boletín de Procedimientos, parecían contar con pocos miembros, excepto la de los Mártires del Deber n. 158, de Lora del Río que llegó a tener 72 masones. La logia Verdad n. 115, perteneciente a otra Obediencia, el Gran Oriente Español, tendrá 164 en esas mismas fechas.

(37) Artículo citado en nota 23 (ENRIQUEZ DEL ARBOL, E.: "Al filo de un centenario..., en Masoneria, Revolución y Reacción, Alicante, Diputación Provincial, 1990, pp. 989-1017). 
Entre otras actuaciones, la Masonería sevillana va a protestar en contra del proyecto de ley presentado por el Gobierno conservador a la Cámara de Diputados con el supuesto deseo de represión del anarquismo:

"Si ese proyecto se examina en su articulado con detenimiento se verá que es un atentado a las libertades que hoy disfrutamos, pues, bien claro se desprende de su contenido que todas las asociaciones, reuniones de cualquier clase que sean así como la rensa periódica quedan a merced de cualquier Gobernador civil mal intencionado, alcalde o cacique, en suma una ley de sospechosos".

"La Masonería en unión de los partidos liberales y republicanos debe protestar por cuantos medios concede la constitución para que no se apruebe su articulado, pues de aprobarse, la vindicta pública masónica debe hacer sentir su peso y su valimiento a los poderes públicos".

"Nada más lógico que se persiga y se castigue a los criminales a los bandidos que arrojan a la vía pública bombas que causan la muerte de infelices e inocentes criaturas, que también la Log. "Verdad" protesta de esos actos vandálicos (...)" (38).

De acuerdo con esta idea, se rechazaba el filibusterismo con el que era acusada la Masonería:

"Los fines (de la Masonería) son más altos o más sublimes y por eso estamos de acuerdo en que nada hay de filusterismo en el Gran Or. Español, sin que vosotros los manifestáseis, lo conceptuábamos así y si alguno que por llamarse masón trabajara a ese fin merecería la reprobación de todos los buenos masones. Nuestras aspiraciones son más altas, la tea de la discordia no se aviene con la filantropía de la hidalga masonería, se quiere la igualdad del hombre, pues del hombre verdad, no del hombre de corazón de fiera. La Masonería trabaja con la razón por sus grandes fines legales, pero no con la tea incendiaria. Es necesario hacer ver a la prensa profana que está en un error, como igualmente el enemigo común que está equivocado (...)" (39).

Se recordará por la logia Minerva $n$. 70 de Herrera, que a la Masonería se debía el actual desarrollo democrático (40). Y en la felicitación que se hizo al nuevo Gran Maestre de la Orden por su elec-

(38) Plancha de la logia Verdad n. 115 al Gran Consejo de la Orden, 2-VII-1896 (Colección documental de la logia Verdad n. 115, de Sevilla, A.H.N. - S.G.C. (Masonería), Legajo 512-A).

(39) Ibidem.

(40) B.P., Año III, n. 26, 29-VI-1891, Sección Oficial, p. 6. 
ción, D. Fernando Lozano, que era director de las Dominicales del Libre pensamiento, se decía:

"Es un infatigable campeón de la república y del librepensamiento de quien espera la masonería muchos y abundantes frutos. De la manera que se ha conducido entre hermanos y correligionarios deducimos con regocijo que la fraternidad entre los más. sin distinción de Ritos está asegurada con solo hallarse al frente de la Mas. de Rito Oriental (...)" (41).

Además se dirigió en otra carta al Círculo de Unión Republicana de la villa, para expresarle el sentimiento que a todos había causado "la pérdida irreparable del ilustre ciudadano Ramón Chies", por el que la logia adoptó el acuerdo de vestir de luto por espacio de un año con motivo de tan funesto suceso (42).

Entre las escasas noticias que nos da la documentación conservada acerca de las confidencias entre masones y refiriéndose a un partido político concreto, tenemos una carta en la documentación de la Verdad $n$. 115, en 1893, en la que el Venerable Juan Larios Salvador, responderá al gran Secretario, Joaquín Ruiz, sobre la información pedida por éste sobre el partido posibilista. En ella confesará, trasluciendo el pragmatismo político de los masones sevillanos, que había pertenecido a este partido hasta hacía dos años, que no hallándose conforme con la política de sus prohombres, había dejado de concurrir a las reuniones, motivo por el cual no había podido responder del estado del partido cuando el Secretario le preguntó personalmente:

"E (sic) visto a Santigosa y me a (sic) dicho que todos permanecen republicanos sin perjuicio de apollar (sic) la política del Sr Sagasta y jurando y perjurando que en nada en (sic) cambiado en su modo de ser. Hoy han tenido una reunión el Gobierno Civil invitados por el Ser. Governador (sic) los prohombres del partido liberal para designar al gefe que en esta a (sic) de gobernar el partido, fue citado D. Luis del Río y D. Pedro Rez. de la Borbolla para que asistiesen a la reunión, los cuales se an (sic) negado prestestando que ellos no pertenecen al partido liberal por más que lo apollen (sic) en todo lo que concierne a su política".

"Es cuanto puedo hoy manifestaros sin perjuicio de teneros al corriente de cuanto ocurra con el partido caso que lo necesitéis pues al presente los que seguimos siendo berdaderos (sic) republicanos somos los soldados de segunda fila como me pasa a mi! (...) (43).

(41) Plancha de la logia Minerva $n$. 70, al Il. y Pod. H.D. Isidro Villarino, 21-XI-1893 (B.P., Año V, n. 24, 30-XII-1893, "Sección Oficial", p. 14).

(42) Ibidem.

(43) Carta de Juan Larios a D. Joaquín Ruiz, 22-X-1893 (Colección documental de la Verdad n. 115, loc. cit.). 
La logia Martía moviéndose doctrinalmente dentro de la ortodoxia, es decir, consagrando el precepto del apoliticismo, reconocerá no obstante el influjo que la Institución podía tener sobre la sociedad:

"Aunque en el templo donde trabaja la Masonería no le es dado por su constitución y forma, mezclarse en política, puede en el mundo profano poner su influjo democrático por excelencia encaminando a estos hacia el progreso en todas sus manifestaciones, constituyendo así con el tiempo buenos Gobiernos firmes y estables, y sostén de los derechos individuales y con ellos, la paz, la armonía y solidaridad" (44).

Los mismos masones de Marchena fundaron un periódico en que se atacaba la desmoralización administrativa de la localidad. Ante la hostilidad provocada, se salieron de la redacción y hubieron de reunirse en grupos dispuestos a repeler la agresión con la fuerza. No paró aquí todo, pues se les llevó a los tribunales, de los que salieron absueltos. De aquella campaña periodística, dirian, se valieron para desenmascarar algunos "caciquillos" que sólo vivían de la "estafa administrativa" (45).

Llama la atención, por otra parte, el origen que daban al anarquismo surgido de La Haya, al que condenarán con los más duros epítetos, colocándolo junto a la escoria social "vívora (sic) que se revuelve alimentada por los Loyolas en el seno de todas las ideas". Y presentarán una historia rocambolesca culpando a los jesuítas de la división de la Internacional en 1872, siendo Bakunin una de sus piezas:

"Sabido es que en Londres nació la Internacional en Septiembre del 64; como sabida la intervención de los Jesuítas en el Congreso de la Haya en septiembre del 72. Allí dirigieron la gran oposición a Carlos Marx, que trajo por resultado su división en "autoritaria" y "federal anarquista". Al frente de la primera colocóse Marx y de la segunda Bakunine. La primera no es revolucionaria: La segunda dirigida en general por el General de los Jesuítas, sirviéndose de ella para provocar desde las sombras todos los conflictos dirigiéndolas a todo género de abusos al derecho, par desacreditar la idea de trabajadores y obreros que ban (sic) por el camino de la redención con el abuso de la desenfrenada bullanga al motín, creando las perturbaciones consi-

(44) ¿Qué debe hacer la masonería para combatir eficazmente la influencia del jesuitismo? Trabajo de logia por Arturo Colás Villuendas, Magallanes, 1892 (Colección documental de la Martia n. 385, de Marchena, loc. cit.).

(45) Memoria-Extracto de los trabajos realizados por la Martía desde Octubre de 1889 a Marzo de 1890, 14-III-1890 (Colección documental de la logia Martía n. 385, de Marchena, A.H.N. - S.G.C. (Masonería), Legajo 774-A-13). 
guientes contra los Gobiernos que no sustenten la retrógrada idea del robustecimiento de la teocracia espiritual del Papa" (46).

\section{CONCLUSIONES}

I. La Masonería como institución democrática persigue la emancipación pacífica y progresiva de todos los seres humanos, constituye una escuela de libertades democráticas o foro de encuentro de determinados ideales progresistas y centro de instrucción socializante con derivaciones políticas. Preconiza en la perfección del hombre y de la sociedad a través del lema Libertad, Igualdad, Fraternidad y ello se plasmará de modo individual en adhesiones o simpatías a partidos políticos progresistas y democráticos.

II. En el período del Sexenio, entre los masones sevillanos con actividad política destacan en número mayoritario los republicanos, seguido de los progresistas y de los monárquicos. Sospechamos que esta combinación puede aplicarse a períodos posteriores relativamente cercanos. Destacamos dos características de acuerdo con la especial idiosincrasia que informa la Masonería a sus miembros: el papel conciliador de los masones de cualquier partido que fuesen y la búsqueda de una República con orden, en 1873.

III. El ejemplo de Ruiz Zorrilla, su giro del progresismo radical al republicanismo, tras la abdicación de Amadeo I, sirvió de modelos a muchos masones que le fueron modelo a muchos masones que le fueron fieles y llevaron su apellido como nombre simbólico (47).

IV. La falta de documentación de contenido "político" en la década de los 80, nos impide saber cual fuese la posición de los masones de Huelva y Sevilla, aunque podemos suponer que en esa etapa tanto unos como otros se inclinarían mayoritariamente por el republicanismo. Casi un $30 \%$ de los nombres simbólicos escogidos por los masones onubenses del período, en la logia más importante, son republica-

(46) Tema 2. ¿De qué medios debía valerse la Masonería para procurar concluir con los privilegios de que disfrutan las Ordenes Monásticas?", por Pithâgoras, gr. 1. 1892 (Colección documental de la Martía n: 385, loc. cit.).

(47) Declararía que era republicano "porque sólo dentro de la República podían los partidos espanoles defender sus doctrinas traducir en leyes sus aspiraciones, desenvolver desde el Gobierno las leyes que habian sido aceptadas por la opinión". Esta afirmación de Ruiz Zorrilla podría ser refrendada por muchos masones y en los textos de los Boletines, de los Grandes Orientes, sobre todo los de la última década, que hacen referencia a cuestiones socio-políticas, la República se presenta como un objetivo primordial a realizar. 
nos. Detectamos simpatías por los masones militares que se sublevaron, en especial por Villacampa.

V. Observamos que a los únicos partidos a los que se alude en la correspondencia sostenida entre las logias andaluzas y los Grandes Orientes, son el republicano posibilista, después fusionista, del que era jefe Morayta y el republicano federal.

VI. Desde 1891 la posición de las bases es mucho más clara hacia el republicanismo, aunque no en todas las logias. Y serán los talleres bajo los dos Grandes Orientes, el Español y la Gran Logia Simbólica Española, los que nos indiquen de forma más evidente, en la última década del siglo, una inclinación por la forma republicana. En definitiva, el desplazamiento hacia la izquierda (desde el progresismo al republicanismo) es visible no sólo en las altas instancias de los Grandes Orientes de los últimos años de la Restauración, sino también en las bases, cuando en algunos momentos éstas, incluso, van más allá de lo sustentado por aquéllas. La declaración de un republicanismo activista consustancial al masón, como expresa una logia de Huelva, es superado por un anarquismo que será posiblemente admitido en Minas de Riotinto mientras había sido execrado en Marchena.

VII. La Masonería estudiada en Sevilla y Huelva para esta etapa de la Restauración, no ofrece en líneas generales, a nuestro entender, una invalidación del principio del "apoliticismo" de la Institución como colectivo, y no hay ningún documento en que se inste a los masones de una logia a declararse o adherirse a algún partido concreto. Sí existen simpatías respecto a movimientos políticos que estuviesen de acuerdo con el espíritu de la Masonería, siendo ello perfectamente admisible. Recordemos el arco político en el que se movían los masones. Dicho esto, debemos añadir que en los últimos años de la Restauración, a fines de siglo, encontramos una desviación de la doctrina, cuando hay claros indicios de una "politización" que se da desde la Obediencia a algunos talleres hasta la determinación demasiado concreta de los principios de la Orden por parte de algunas logias, derivando en ambos casos hacia el partidismo, lo cual estaba reñido con la "ortodoxia" masónica.

VIII. Esta relación de Masonería-Republicanismo debe ser estudiada en los niveles de miembros, logias y Obediencias, en las distintas regiones españolas y en las diferentes etapas históricas a la par que se investigue sobre esa conexión de los masones con la vida política del XIX. Sólo así podremos completar y elevar a definitivas estas conclusiones. 